\title{
Sphingomonas pseudosanguinis sp. nov., isolated from the water reservoir of an air humidifier
}

Correspondence

Peter Kämpfer

peter.kaempfer@agrar.

uni-giessen.de

\author{
Peter Kämpfer, ${ }^{1}$ Uwe Meurer, ${ }^{2}$ Michael Esser, ${ }^{3}$ Thomas Hirsch $^{3}$ \\ and Hans-Jürgen Busse ${ }^{4}$
}

\author{
${ }^{1}$ Institut für Angewandte Mikrobiologie, Justus-Liebig-Universität, D-35390 Giessen, Germany \\ ${ }^{2}$ Technical Department, MEDISANA AG, D-40724 Hilden, Germany \\ ${ }^{3}$ Stadtwerke Solingen GmbH, T 3.2 Labor, D-42699 Solingen, Germany \\ ${ }^{4}$ Institut für Bakteriologie, Mykologie und Hygiene, Veterinärmedizinische Universität Wien, \\ A-1210 Wien, Austria
}

\begin{abstract}
A yellow-pigmented bacterial isolate, strain $\mathrm{G} 1-2^{\top}$, obtained from the surface of an air humidifier, was characterized taxonomically. 16S rRNA gene sequence analysis, physiological characterization and estimation of the ubiquinone and polar lipid patterns and fatty acid composition revealed that strain $\mathrm{G} 1-2^{\top}$ was similar to Sphingomonas yabuuchiae and Sphingomonas sanguinis, but also showed pronounced differences. On the basis of these results, a novel species of the genus Sphingomonas is described, for which the name Sphingomonas pseudosanguinis sp. nov. is proposed. The type strain is G1-2 ${ }^{\top}$ (=CCUG $54232^{\top}=$ CIP $\left.109431^{\top}\right)$.
\end{abstract}

The genus Sphingomonas, proposed by Yabuuchi et al. (1990), contains Gram-negative, non-fermentative rods that are characterized chemotaxonomically by the presence of ubiquinone Q-10, sym-homospermidine as the key polyamine, a lipid pattern consisting of phosphatidylethanolamine (with the exception of Sphingomonas echinoides DSM $1805^{\mathrm{T}}$; Denner et al., 1999), phosphatidylglycerol, diphosphatidylglycerol, sphingoglycolipid and phosphatidylcholine as the major lipids and by the presence of 2-hydroxymyristic acid (2-OH 14:0) and the absence of 3-hydroxy fatty acids in their fatty acid profiles (Busse et al., 1999; Takeuchi et al., 2001; Zhang et al., 2005; Yoon et al., 2006). Members of the genus Sphingomonas have been isolated from clinical samples, for example Sphingomonas sanguinis (Yabuuchi et al., 1990: Takeuchi et al., 1993), and also from some very unusual environments such as the Russian space laboratory Mir, from where Sphinogmonas yabuuchiae was isolated ( $\mathrm{Li}$ et al., 2004). In this study, we describe a novel species of the genus Sphingomonas that shows an intermediate position between $S$. sanguinis and $S$. yabuuchiae on the basis of a polyphasic characterization.

Strain G1-2 $2^{\mathrm{T}}$ was isolated from the water reservoir of an air humidifier (Medibreeze 60002; Medisana) on DEV nutrient agar at $36^{\circ} \mathrm{C}$. The novel strain was isolated after several unsuccessful attempts to disinfect the air humidifier.

Abbreviations: pNA, para-nitroanilide; pNP, para-nitrophenol.

The GenBank/EMBL/DDBJ accession number for the $16 \mathrm{~S}$ rRNA gene sequence of strain $\mathrm{G} 1-2^{\top}$ is $\mathrm{AM} 412238$.
The novel strain was maintained on nutrient agar (Oxoid) at $30{ }^{\circ} \mathrm{C}$ and showed a yellow pigmentation when grown on this medium. Cells of strain G1-2 ${ }^{\mathrm{T}}$ stained Gram-negative with the modified Hucker method (Gerhardt et al., 1994). Cell morphology was observed under a Zeiss light microscope at $\times 1000$ using cells grown for $24 \mathrm{~h}$ at $30^{\circ} \mathrm{C}$ on Medium 65 (DSMZ). The 16S rRNA gene sequence was analysed as described by Kämpfer et al. (2003). Phylogenetic analysis was performed using the MEGA version 3.0 software package (Kumar et al., 2004) after multiple alignment of the data by CLUSTAL_X (Thompson et al., 1997). Distances (distance options according to the Kimura-2 model) and clustering with the neighbour-joining and maximumparsimony methods were performed by using bootstrap values based on 1000 replications (Fig. 1). The 16S rRNA gene sequence of strain G1-2 ${ }^{\mathrm{T}}$ was a continuous stretch of $1371 \mathrm{bp}$. Sequence similarity calculations performed after a neighbour-joining analysis indicated that the closest relatives of strain GW1-2 ${ }^{\mathrm{T}}$ were S. sanguinis IFO $13937^{\mathrm{T}}$ (GenBank accession no. D13726) with 99.2\% sequence similarity, S. yabuuchiae A1-18 ${ }^{\mathrm{T}}$ (AB071955), 99.2\% similarity, and Sphingomonas parapaucimobilis JCM $7510^{\mathrm{T}}$ (D84525), 99.1\% similarity. Lower sequence similarities ( $<98 \%$ ) were found with all other recognized species of the genus Sphingomonas.

Chemotaxonomic analyses were performed as follows. Respiratory quinones and polar lipids were determined according to Tindall $(1990 \mathrm{a}, \mathrm{b})$ and Altenburger et al. (1996), respectively. Polyamines were analysed as described by Busse \& Auling (1988) and Stolz et al. (2007). 


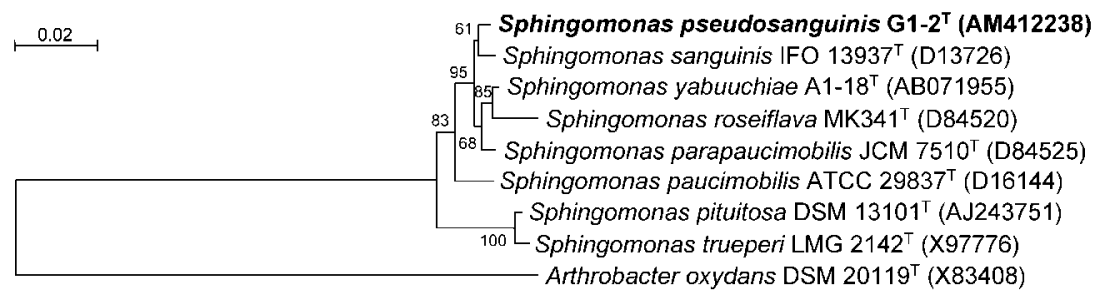

Fig. 1. Phylogenetic analysis based on $16 \mathrm{~S}$ rRNA gene sequences available from the EMBL database (accession nos are given in parentheses) constructed after multiple alignment of data by CLUSTAL_X (Thompson et al., 1997). Distance (distance options according to the Kimura-2 model) and clustering with the neighbour-joining method were performed by using the MEGA version 3.0 software package (Kumar et al., 2004). Bootstrap values based on 1000 replications are given as percentages at the branching points. Bar, 0.02 nucleotide substitutions per nucleotide position.

The detection of a quinone system consisting of ubiquinone Q-10 (96\%) and Q-9 (4\%) for strain G1-2 ${ }^{\mathrm{T}}$ was in accordance with the characteristics of species of the genus Sphingomonas sensu stricto and of the family Sphingomonadaceae (Busse et al., 1999; Kosako et al., 2000). The polyamine pattern showed a predominance of the symhomospermidine $\left[48.3 \mu \mathrm{mol}\right.$ ( $\mathrm{g}$ dry weight) ${ }^{-1}$, the key characteristic of Sphingomonas sensu stricto (Busse et al., 1999; Takeuchi et al., 2001), and minor amounts of spermidine $\left[1.0 \mu \mathrm{mol}(\mathrm{g} \text { dry weight })^{-1}\right]$ and putrescine $\left.[0.1 \mu \mathrm{mol} \text { (g dry weight })^{-1}\right]$. The polar lipid profiles of strain G1-2 ${ }^{\mathrm{T}}$ contained the major compounds phosphatidylethanolamine, phosphatidylglycerol, diphosphatidylglycerol, sphingoglycolipid, phosphatidylcholine, a highly hydrophilic unknown glycolipid GL1 and an unknown phospholipid. Another highly hydrophobic unknown glycolipid GL2, an unknown aminophosphoglycolipid and an unknown polar lipid were also detected in moderate amounts. Minor to trace amounts of phosphatidyldimethylethanolamine and three unknown polar lipids were also detected (Fig. 2). This profile is in excellent agreement with the characteristics found for species of the genus Sphingomonas sensu stricto (Busse et al., 1999). The absence of phosphatidylmonomethylethanolamine, as well as presence of only minor amounts of phosphatidyldimethylethanolamine, are in agreement with the characteristics of the close phylogenetic neighbour S. sanguinis and are useful characteristics for distinguishing the novel strain $\mathrm{G} 1-2^{\mathrm{T}}$ from the majority of other species of the genus Sphingomonas (Busse et al., 1999, 2005). However, the presence of an unknown aminophosphoglycolipid and the presence of only a single sphingoglycolipid in strain $\mathrm{G} 1-2^{\mathrm{T}}$ enables it to be differentiated unambiguously from $S$. sanguinis which shows a profile containing an unknown glycolipid (GL1) assumed to represent another sphingoglycolipid (Busse et al., 1999).

GC was used to analyse the fatty acid profiles of the strain, as described previously (Kämpfer \& Kroppenstedt, 1996; Kämpfer et al., 1997). Strain G1-2 ${ }^{\mathrm{T}}$ showed a fatty acid profile typical for members of this genus with $2-\mathrm{OH} \mathrm{C}_{14: 0}$ as the key hydroxylated fatty acid (Table 1).
Physiological and biochemical characterizations were performed according to previously described procedures (Kämpfer et al., 1991, 1997).

Strain $\mathrm{G} 1-2^{\mathrm{T}}$ is capable of assimilating several carbon sources and the utilization profile is similar to that of $S$. sanguinis and S. yabuuchiae. However, strain $\mathrm{G} 1-2^{\mathrm{T}}$ could be differentiated from S. sanguinis and S. yabuuchiae on the basis of several carbon substrate utilization tests (Table 2). Due to the high similarity of strain $\mathrm{G} 1-2^{\mathrm{T}}$ to S. sanguinis and S. yabuuchiae, DNA-DNA hybridization experiments were

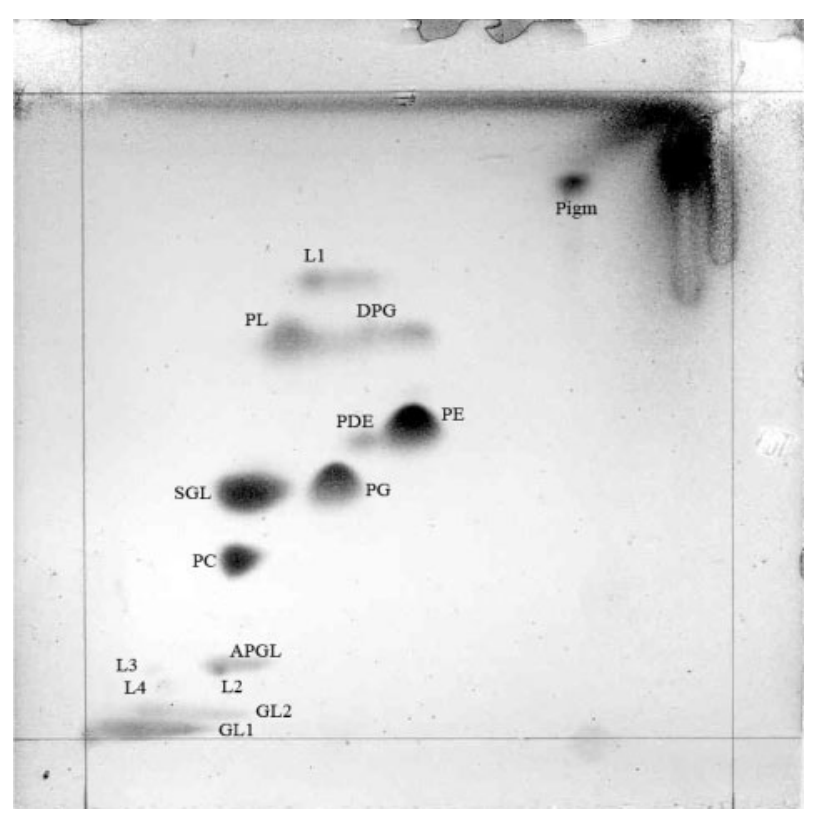

Fig. 2. Polar lipid profile of strain $\mathrm{G} 1-2^{\top}$ after two-dimensional TLC and detection with molybdatophosphoric acid. DPG, diphosphatidylglycerol; PG, phosphatidylglycerol; PE, phosphatidylethanolamine; PDE, phosphatidyldimethylethanolamine; PC, phosphatidylcholine; SGL, sphingoglycolipid; PL, unknown phospholipid; GL1-2, unknown glycolipids; L1-4, unknown polar lipids; Pigm, yellow pigment. 
Table 1. Fatty acid content of selected species of the genus Sphingomonas

Taxa: 1, strain $\mathrm{G} 1-2^{\mathrm{T}}$; 2, S. sanguinis IFO $13937^{\mathrm{T}}$; 3, S. yabuuchiae A1- $18^{\mathrm{T}}$; 4, S. paucimobilis ATCC $29837^{\mathrm{T}}$; 5, S. parapaucimobilis JCM $7510^{\mathrm{T}}$; 6, S. trueperi ATCC $12417^{\mathrm{T}}$. Values are percentages of total fatty acids. tr, Trace $(<1.0 \%) ;-$, not detected. Data are taken from the present study and Denner et al. (2001). Summed features represent groups of two or three fatty acids that could not be separated by GLC with the MIDI system (Microbial ID). Summed feature 4 contains one or more of the following fatty acids: $16: 1 \omega 7 t, 15: 0$ iso $2-\mathrm{OH}$ and $16: 1 \omega 7 c$. Summed feature 7 contains one or more of the following fatty acids: $18: 1 \omega 7 c$, $18: 1 \omega 9 t$ and/or $18: 1 \omega 12 t$.

\begin{tabular}{|lcccccc|}
\hline Fatty acid & $\mathbf{1}$ & $\mathbf{2}$ & $\mathbf{3}$ & $\mathbf{4}$ & $\mathbf{5}$ & $\mathbf{6}$ \\
\hline $14: 0$ & 1.0 & 1.0 & 1.3 & 1.4 & 1.0 & - \\
$14: 02-\mathrm{OH}$ & 5.4 & 6.7 & 8.7 & 6.4 & 5.0 & 6.7 \\
$15: 0$ & - & - & - & - & 1.1 & - \\
$16: 0$ & 12.9 & 9.6 & 9.9 & 8.7 & 13.6 & 9.8 \\
$16: 1 \omega 5 c$ & - & 1.9 & $\operatorname{tr}$ & - & 1.0 & - \\
Summed feature 4 & 4.8 & 8.6 & 5.9 & 2.7 & 6.7 & - \\
$17: 0$ & - & - & 1.2 & - & 0.5 & 1.6 \\
$17: 1 \omega 6 c$ & 0.8 & 3.8 & 5.1 & 3.0 & 2.4 & 13.6 \\
$18: 0$ & 1.6 & - & $\operatorname{tr}$ & - & 0.6 & - \\
Summed feature 7 & 72.0 & 65 & 62.5 & 74.6 & 64.6 & 64.2 \\
$18: 1 \omega 5 c$ & 1.4 & 3.5 & 2.3 & 3.2 & 3.5 & 4.0 \\
& & & & & & \\
\hline
\end{tabular}

performed with the type strains of these two species using the method described by Ziemke et al. (1998), except that for nick translation $2 \mu \mathrm{g}$ of DNA was labelled during a $3 \mathrm{~h}$ incubation at $15^{\circ} \mathrm{C}$. Strain G1-2 ${ }^{\mathrm{T}}$ showed relatively low DNA-DNA relatedness values to S. sanguinis IFO $13937^{\mathrm{T}}$ (46\%; reciprocal $39.6 \%$ ) and S. yabuuchiae DSM $14562^{\mathrm{T}}$ (51.9\%; reciprocal $43.2 \%)$.

On the basis of the 16S rRNA gene sequence analysis, DNADNA hybridization values and phenotypic data, we propose that strain $\mathrm{G} 1-2^{\mathrm{T}}$ represents a novel species, Sphingomonas pseudosanguinis sp. nov.

\section{Description of Sphingomonas pseudosanguinis sp. nov.}

Sphingomonas pseudosanguinis (pseu.do.san'gui.nis. Gr. adj. pseudos false; L. gen. n. sanguinis of the blood; N.L. gen. n. pseudosanguinis indicating that the strains are similar to Sphingomonas sanguinis).

Cells are rod-shaped, $0.8-1.5 \mu \mathrm{m}$ in length and 0.4-0.6 $\mu \mathrm{m}$ in diameter. Colonies are yellow-coloured. The following are used as substrates for growth: L-arabinose, p-arbutin, Dcellobiose, D-fructose, D-galactose, D-glucose, D-mannose, D-maltose, sucrose, D-trehalose, D-xylose, citrate, fumarate, DL-3-hydroxybutyrate, L-malate, pyruvate, L-alanine, Lleucine and L-proline. $N$-acetyl-D-glucosamine, gluconate, $\alpha$-D-melibiose, L-rhamnose, ribose, salicin, D-adonitol, maltitol, D-mannitol, D-sorbitol, acetate, propionate,
Table 2. Differentiating characteristics of strain $G 1-2^{\top}$ and related sym-homospermidine-containing Sphingomonas species

Taxa: 1, strain G1-2 ${ }^{\mathrm{T}} ; 2$, S. yabuuchiae DSM $24562^{\mathrm{T}} ; 3$, S. sanguinis IFO $13937^{\mathrm{T}}$; 4, Sphingomonas pituitosa $\mathrm{EDIV}^{\mathrm{T}}$; 5, Sphingomonas trueperi ATCC $12417^{\mathrm{T}} ; 6$, S. paucimobilis ATCC $29837^{\mathrm{T}}$; 7, S. parapaucimobilis JCM $7510^{\mathrm{T}} ; 8$, Sphingomonas roseiflava IAM $14832^{\mathrm{T}}$. All data were obtained using the same method (Kämpfer et al., 1991). + , Positive; $(+)$, weakly positive; -, negative; pNA, para-nitroanilide; pNP, para-nitrophenol. Data for strain $\mathrm{G1}-2^{\mathrm{T}}$, S. yabuuchiae and S. roseiflava are from this study. All other data are from Kämpfer et al. (1997) and Denner et al. (2001). All taxa were negative in tests for acid production from D-mannitol and trehalose.

\begin{tabular}{|c|c|c|c|c|c|c|c|c|}
\hline Characteristic & 1 & 2 & 3 & 4 & 5 & 6 & 7 & 8 \\
\hline \multicolumn{9}{|l|}{ Acid produced from: } \\
\hline Cellobiose & - & - & - & $(+)$ & - & $(+)$ & $(+)$ & - \\
\hline Glucose & - & $(+)$ & - & $(+)$ & - & - & - & - \\
\hline Maltose & - & - & - & $(+)$ & - & $(+)$ & $(+)$ & - \\
\hline D-Mannose & - & - & - & - & - & $(+)$ & $(+)$ & - \\
\hline Melibiose & - & - & - & - & - & $(+)$ & $(+)$ & - \\
\hline Methyl D-glucoside & - & - & - & - & - & + & - & - \\
\hline Rhamnose & - & - & - & - & - & - & $(+)$ & - \\
\hline Salicin & - & - & - & - & - & + & - & - \\
\hline Sorbitol & - & - & - & - & + & - & - & - \\
\hline D-Xylose & - & - & - & $(+)$ & - & + & $(+)$ & - \\
\hline \multicolumn{9}{|l|}{ Hydrolysis of: } \\
\hline Aesculin & + & + & - & + & - & $(+)$ & $(+)$ & + \\
\hline L-Alanine pNA & + & + & + & + & - & + & + & + \\
\hline pNP $\beta$-D-glucuronide & - & $(+)$ & + & + & + & - & + & - \\
\hline pNP phosphorylcholine & + & - & + & + & + & - & + & - \\
\hline L-Proline pNA & + & + & - & - & - & - & + & + \\
\hline \multicolumn{9}{|l|}{ Assimilation of: } \\
\hline Acetate & - & + & + & + & + & - & + & - \\
\hline cis-Aconitate & - & + & - & - & - & + & + & + \\
\hline trans-Aconitate & - & + & - & - & - & + & - & + \\
\hline L-Alanine & + & + & + & + & + & - & + & $(+)$ \\
\hline L-Aspartate & - & - & + & - & + & - & - & - \\
\hline Citrate & + & + & - & - & - & - & + & - \\
\hline D-Fructose & + & + & + & - & + & - & - & + \\
\hline Fumarate & + & + & + & + & + & + & - & + \\
\hline Gluconate & - & + & - & - & - & - & + & + \\
\hline Glutarate & + & + & - & - & + & - & + & - \\
\hline 4-Hydroxybenzoate & - & - & - & - & + & - & - & - \\
\hline DL-3-Hydroxybutyrate & + & + & + & + & + & - & + & + \\
\hline DL-Lactate & - & + & + & - & + & - & + & - \\
\hline L-Leucine & + & - & + & - & + & - & + & $(+)$ \\
\hline Maltitol & - & + & + & - & + & - & - & - \\
\hline$\alpha$-D-Melibiose & - & + & + & + & + & - & + & - \\
\hline L-Ornithine & - & - & + & - & - & - & - & - \\
\hline Oxoglutarate & + & + & + & - & - & + & + & + \\
\hline L-Proline & + & + & + & + & - & - & - & + \\
\hline Propionate & - & - & + & - & + & - & + & - \\
\hline L-Rhamnose & - & - & - & - & - & - & $(+)$ & - \\
\hline Salicin & - & + & + & + & + & - & + & - \\
\hline L-Serine & - & - & - & - & + & - & - & - \\
\hline
\end{tabular}


azelate, cis-aconitate, adipate, 4-aminobutyrate, DL-lactate, L-aspartate, L-histidine, L-ornithine, L-phenylalanine, Ltryptophan, 3-hydroxybenzoate, 4-hydroxybenzoate and phenylacetate are not used as substrates. Positive in tests for the hydrolysis of aesculin, pNP $\alpha$-D-glucopyranoside, pNP $\beta$-D-glucopyranoside, pNP $\beta$-D-galactopyranoside, bis-pNP phosphate, pNP phenyl phosphonate, 2-deoxythymidine- $5^{\prime}-\mathrm{pNP}$ phosphate, pNP phosphorylcholine, Lalanine pNA, L-glutamate- $\gamma$-3-carboxy-pNA and L-proline pNA. pNP $\beta$-D-glucuronide is not hydrolysed. The main polar lipids are phosphatidylethanolamine, phosphatidylglycerol, diphosphatidylglycerol, sphingoglycolipid, phosphatidylcholine, a highly hydrophilic unknown glycolipid GL1 and an unknown phospholipid. The species is characterized by the major fatty acids 18:1 (Summed feature 7) and 16:0. Minor fatty acids are 14:0, 18:0, $17: 1 \omega 6 c$ and $18: 1 \omega 5 c$. The major hydroxy-fatty acid is 2-hydroxy-14:0. The major polyamine is sym-homospermidine with the following minor polyamines: diaminopropane, putrescine, cadaverine, spermidine and spermine. Produces predominantly ubiquinone Q-10.

The type strain, G1-2 ${ }^{\mathrm{T}}\left(=\right.$ CCUG $54232^{\mathrm{T}}=$ CIP $\left.109431^{\mathrm{T}}\right)$, was isolated from the surface of an air humidifier.

\section{References}

Altenburger, P., Kämpfer, P., Makristathis, A., Lubitz, W. \& Busse, H.-J. (1996). Classification of bacteria isolated from a medieval wall painting. J Biotechnol 47, 39-52.

Busse, H. J. \& Auling, G. (1988). Polyamine pattern as a chemotaxonomic marker within the Proteobacteria. Syst Appl Microbiol 11, $1-8$.

Busse, H.-J., Kämpfer, P. \& Denner, E. B. M. (1999). Chemotaxonomic characterisation of Sphingomonas. J Ind Microbiol Biotechnol 23, 242-251.

Busse, H.-J., Hauser, E. \& Kämpfer, P. (2005). Description of two novel species, Sphingomonas abaci sp. nov. and Sphingomonas panni sp. nov. Int J Syst Evol Microbiol 55, 2565-2569.

Denner, E. B. M., Kämpfer, P., Busse, H.-J. \& Moore, E. R. B. (1999), Reclassification of Pseudomonas echinoides Heumann 1962, 343 ${ }^{\mathrm{AL}}$, in the genus Sphingomonas as Sphingomonas echinoides comb. nov. Int J Syst Bacteriol 49, 1103-1109.

Denner, E. B. M., Paukner, S., Kämpfer, P., Moore, E. R. B., Abraham, W. R., Busse, H.-J., Wanner, G. \& Lubitz, W. (2001). Sphingomonas pituitosa sp. nov., an exopolysaccharide-producing bacterium that secretes an unusual type of sphingan. Int J Syst Evol Microbiol 51, 827-841.

Gerhardt, P., Murray, R. G. E., Wood, W. A. \& Krieg, N. R. (editors) (1994). Methods for General and Molecular Bacteriology. Washington, DC: American Society for Microbiology.

Kämpfer, P. \& Kroppenstedt, R. M. (1996). Numerical analysis of fatty acid patterns of coryneform bacteria and related taxa. Can J Microbiol 42, 989-1005.

Kämpfer, P., Steiof, M. \& Dott, W. (1991). Microbiological characterisation of a fuel-oil contaminated site including numerical identification of heterotrophic water and soil bacteria. Microb Ecol 21, 227-251.

Kämpfer, P., Denner, E. B. M., Meyer, S., Moore, E. R. B. \& Busse, H.-J. (1997). Classification of "Pseudomonas azotocolligans" Anderson 1955, 132, in the genus Sphingomonas as Sphingomonas trueperi sp. nov. Int J Syst Bacteriol 47, 577-583.

Kämpfer, P., Dreyer, U., Neef, A., Dott, W. \& Busse, H.-J. (2003). Chryseobacterium defluvii sp. nov., isolated from wastewater. Int J Syst Evol Microbiol 53, 93-97.

Kosako, Y., Yabuuchi, E., Naka, T., Fujiwara, N. \& Kobayashi, K. (2000). Proposal of Sphingomonadaceae fam. nov., consisting of Sphingomonas Yabuuchi et al. 1990, Erythrobacter Shiba and Shimidu 1982, Erythromicrobium Yurkov et al. 1994, Porphyrobacter Fuerst et al. 1993, Zymomonas Kluyver and van Niel 1936, and Sandaracinobacter Yurkov et al. 1997, with the type genus Sphingomonas Yabuuchi et al. 1990. Microbiol Immunol 44, 563-575.

Kumar, S., Tamura, K. \& Nei, M. (2004). MEGA3: Integrated software for Molecular Evolutionary Genetics Analysis and sequence alignment. Brief Bioinform 5, 150-163.

Li, Y., Kawamura, Y., Fujiwara, N., Naka, T., Liu, H., Huang, X., Kobayashi, K. \& Ezaki, T. (2004). Sphingomonas yabuuchiae sp. nov. and Brevundimonas nasdae sp. nov., isolated from the Russian space laboratory Mir. Int J Syst Evol Microbiol 54, 819-825.

Stolz, A., Busse, H.-J. \& Kämpfer, P. (2007). Pseudomonas knackmussii sp. nov. Int J Syst Evol Microbiol 57, 572-576.

Takeuchi, M., Kawai, F., Shimada, Y. \& Yokota, A. (1993). Taxonomic study of polyethylene glycol-utilizing bacteria: amended description of the genus Sphingomonas and new description of Sphingomonas macrogoltabidus sp. nov., Sphingomonas sanguis sp. nov., and Sphingomonas terrae sp. nov. Syst Appl Microbiol 16, 227-238.

Takeuchi, M., Hamana, K. \& Hiraishi, A. (2001). Proposal of the genus Sphingomonas sensu stricto and three new genera, Sphingobium, Novosphingobium and Sphingopyxis, on the basis of phylogenetic and chemotaxonomic analyses. Int J Syst Evol Microbiol 51, 1405-1417.

Thompson, J. D., Gibson, T. J., Plewniak, F., Jeanmougin, F. \& Higgins, D. G. (1997). The CLUSTAL_X windows interface: flexible strategies for multiple sequence alignment aided by quality analysis tools. Nucleic Acids Res 25, 4876-4882.

Tindall, B. J. (1990a). Lipid composition of Halobacterium lacusprofundi. FEMS Microbiol Lett 66, 199-202.

Tindall, B. J. (1990b). A comparative study of the lipid composition of Halobacterium saccharovorum from various sources. Syst Appl Microbiol 13, 128-130.

Yabuuchi, E., Yano, I., Oyaizu, H., Hashimoto, Y., Ezaki, T. \& Yamamoto, H. (1990). Proposals of Sphingomonas paucimobilis gen. nov. and comb. nov., Sphingomonas parapaucimobilis sp. nov., Sphingomonas yanoikuyae sp. nov., Sphingomonas adhaesiva sp. nov., Sphingomonas capsulata comb. nov., and two genospecies of the genus Sphingomonas. Microbiol Immunol 34, 99-119.

Yoon, J.-H., Lee, M.-H., Kang, S.-J., Lee, S.-Y. \& Oh, T. K. (2006). Sphingomonas dokdonensis sp. nov., isolated from soil. Int J Syst Evol Microbiol 56, 2165-2169.

Zhang, Y.-Q., Chen, Y.-G., Li, W.-J., Tian, X.-P., Xu, L.-H. \& Jiang, C.-L. (2005). Sphingomonas yunnanensis sp. nov., a novel Gramnegative bacterium from a contaminated plate. Int $J$ Syst Evol Microbiol 55, 2361-2364.

Ziemke, F., Höfle, M. G., Lalucat, J. \& Rosselló-Mora, R. (1998). Reclassification of Shewanella putrefaciens Owen's genomic group II as Shewanella baltica sp. nov. Int J Syst Bacteriol 48, 179-186. 